\begin{tabular}{l|l|l}
\hline \hline Vol. 24(4):391-398 & Ocean and Polar Research & December 2002 \\
\hline
\end{tabular}

Article

\title{
Trace Organic Contaminants in Sediments from Deep-sea Basin near Dokdo, Korea
}

\author{
Un Hyuk Yim*1, Jae Ryoung $\mathrm{Oh}^{1}$, Sang Hee Hong', Dong Hao Li', Won Joon Shim, \\ Hye Kyung Choi', Eun Soo Kim', and Jae Hyung Shim ${ }^{2}$ \\ ${ }^{1}$ Ecosystem and Environment Research Laboratory, KORDI \\ Ansan P.O. Box 29, Seoul 425-600, Korea \\ ${ }^{2}$ School of Earth \& Environmental Sciences, \\ Seoul National University, Seoul 151-742, Korea
}

\begin{abstract}
Trace organic contaminants in deep-sea sediments near Dokdo were analyzed. Total PAHs concentration ranged 14.8-314 ng/g dry weight and high molecular weight PAHs were dominant. The highest PAHs concentration was detected at A19 which located at Ulleung Basin. Most of organochlorines were under detection limit. Among the detected organochlorines, DDT compounds were dominant and followed by HCHs and HCB. Butyltin compounds and most of organophosphorus pesticides were not detected. Vertical distribution of PAHs showed typical sub-surface maximum and decreasing trends depending on depth. The highest PAHs concentration reached $454 \mathrm{ng} / \mathrm{g}$. Some organochlorines, DDT, HCH was detected and also showed decreasing trends. Other target organic pollutants were not detected in core sediments. Abnormally high level of PAHs concentration in A19 was discussed and the input sources were inferred to be the transport of sludge derived pollutant dumped at dumping site "Byung" by deep current.
\end{abstract}

Key words : Trace organic contaminants, Sediment, Core, Deep-sea, Deep current.

\section{Introduction}

The deep-sea and its ecosystems are considered to be one of the last regions on earth that are little, or not at all, influenced by human activity. But the deep-sea is not as pristine as it is supposed to be, it may even turn out to be the ultimate global sink for persistent organic pollutants in the marine environment, like the soil of the forests is in the terrestrial environment (Krämer et al. 1984; Froescheis et al. 2000). In an aqueous environment, the physicochemical properties of persistent, hydrophobic, semivolatile contaminants require that they accumulate in biota or that they are adsorbed on particles (bio- and geo-accumulation). As a result, persistent organic pollutants will follow any movement of particles or organic matter in the oceanic system and therefore will be transported to the remote sites of the deep-sea as well.

\footnotetext{
*Corresponding author. E-mail : uhyim@kordi.re.kr
}

Deep-sea basin near Dokdo in this study is Ulleung basin where water depth is more than $2,000 \mathrm{~m}$ deep. There are only limited human activity and very limited input of anthropogenic materials. Therefore deep-sea near Dokdo has been thought to be pristine area. In order to understand geographical and vertical distribution of trace organic contaminants in this area, deep-sea sediments were collected and analyzed under strict quality control.

Trace organic contaminants considered here include several categories (Table 1). Polycyclic aromatic hydrocarbons (PAHs) are known to be produced by incomplete combustion processes and are constituents of crude oil or refined products. PAHs originated at high temperatures (pyrogenic) are dominated by the parent species, while crude oils (petrogenic) contain a wide range of alkyl-derivatives. The low molecular weight PAHs have a significant acute toxicity, whereas some the high molecular weight PAHs show high carcinogenic potential (McElroy et al., 1989; Stein et al., 1990). 
Table 1. List of target compounds analyzed in this study.

\begin{tabular}{|c|c|}
\hline Chlorinated Pesticides & $\begin{array}{l}\text { Polycyclic Aromatic } \\
\text { Hydrocarbons }\end{array}$ \\
\hline $\begin{array}{l}\text { Pentachlorobenzene } \\
\text { Hexachlorobenzene }\end{array}$ & $\begin{array}{l}\text { Naphthalene } \\
\text { 2,-Methylnaphthalene } \\
\text { 1-Methylnaphthalene }\end{array}$ \\
\hline $\begin{array}{l}\mathrm{HCHs} \\
\alpha \text {-HCH, } \beta-\mathrm{HCH}, \gamma-\mathrm{HCH}, \\
\delta \text {-HCH }\end{array}$ & $\begin{array}{l}\text { Biphenyl } \\
\text { 2,5-Dimethylnaphthalene } \\
\text { Acenaphthylene } \\
\text { Acenaphthene }\end{array}$ \\
\hline $\begin{array}{l}\text { Chrodane related compounds } \\
\alpha \text {-Chlordane, } \gamma \text {-Clordane, } \\
\text { cis-Nonachlor, trans-Nonachlor, } \\
\text { Oxychlordane, } \\
\text { Heptachlor, Heptachlor epoxide }\end{array}$ & $\begin{array}{l}\text { 2,3,5-Trimethylnaphthalene } \\
\text { Fluorene } \\
\text { Phenanthrene } \\
\text { Anthracene } \\
\text { 1-Methylphenanthrene } \\
\text { Fluoranthene }\end{array}$ \\
\hline $\begin{array}{l}\text { Aldrin, Dieldrin } \\
\text { Endrin } \\
\text { Endosulfan } \\
\text { Mirex }\end{array}$ & $\begin{array}{l}\text { Pyrene } \\
\text { Benz[a]anthracene } \\
\text { Chrysene } \\
\text { Benzo[b+k]fluoranthene } \\
\text { Benzo[e]pyrene }\end{array}$ \\
\hline $\begin{array}{l}\text { DDT compounds } \\
\text { o,p'-DDE, p,p'-DDE, } \\
\text { o,p'-DDD, p,p'-DDD, } \\
\text { o,p'-DDT, p,p'-DDT }\end{array}$ & $\begin{array}{l}\text { Benzo[a]pyrene } \\
\text { Perylene } \\
\text { Indno(1,2,3-cd)pyrene } \\
\text { Dibenz[a,h]anthracene } \\
\text { Benzo[ghi]perylene }\end{array}$ \\
\hline $\begin{array}{l}\text { Polychlorinated Biphenyl } \\
\text { congeners }\end{array}$ & $\begin{array}{c}\text { Butyltin } \\
\text { Compounds }\end{array}$ \\
\hline
\end{tabular}

PCB8, PCB18, PCB28, PCB29, Tributyltin, Dibutyltin, PCB44, PCB52, PCB66, PCB87, Monobutyltin

PCB101, PCB105, PCB110, Organophosphorous PCB118, PCB128, PCB138, Pesticides

PCB153, PCB170, PCB180, Diazin, IBP, Dichlorvos, PCB187, PCB195, PCB200, Parathion, Methylparathion, PCB206, PCB209 chlorpyrifos

Polychlorinated biphenyls (PCBs), organochlorine (OC) pesticides such as hexachlorobenzene (HCB), $\mathrm{HCH}$ isomers (HCHs), Chlordanes (CHLs), DDT, and its derivatives (DDTs) have been detected in sediments for over the last 30 years. Despite a 1970s ban on the use of PCBs and DDTs in many countries including Korea, these compounds are ubiquitous and persistent in various environmental media (Khim et al. 1999).

Organotin compounds are among the most widely used organometallic chemicals. Production of organotins has increased for various purposes since their first biocidal application in the early 1920s (Shim et al. 1999). Tributytin (TBT) used as biocidal additive for antifouling paints has received much attention since its adverse effects on oyster farms near marina were revealed in the early 1980s (Alzieu, 1986). Many industrialized countries have regulated the use of TBT in anti-fouling paints and also banned in Korea since 2000.

In many countries, restrictions have been imposed on the use of organochlorine pesticides. This has shifted the use patterns away from organochlorines toward organophosphorus and carbamate pesticides. Most organophosphorus and carbamate pesticides are regarded as being non-persistent, but residues of some organophosphorus pesticides are persisting for extended periods in organic soils and in surrounding drainage systems (Harris and Miles, 1975).

\section{Materials and methods}

Five surface sediment and one core samples were taken around Dokdo (Fig. 1). The sampling took place during May 2000 cruise of $R / V$ Onuri. Sediment samples were taken using Box corer and sediment core was sampled at St. A19 using acryl liner. The samples were immediately frozen by dry ice and stored at the freezer before laboratory analysis. Packing and storage of the samples followed the normal NS\&T protocol of US NOAA (Lauenstein and Cantillo, 1998).

The analytical procedures of PAHs and organochlorines in sediments followed the method of Sloan et al.(1993) after some modifications. Briefly, The dried sediment samples were spiked with $300 \mathrm{ng}$ of deuterated surrogates for PAHs (naphthalene- $d_{8}$, acenaphthene- $d_{10}$, phenanthrene$d_{10}$, chrysene- $d_{12}$, and perylene- $d_{12}$ ) and 10 ng of surrogate for organochlorines (OCs) (DBOFB, PCB 103, PCB 169) and then extracted by Soxhlet for 6-8 hrs with $200 \mathrm{ml}$ of methylene chloride. The sample extracts were extensively cleaned up by a $\mathrm{Si} / \mathrm{Al}$ column chromatography and HPLC with size exclusion column (Krahn et al., 1988). Terphenyl$d_{14}$ (PAH) and tetrachloro- $m$-xylene (TCMX, OCs) was used as instrumental internal standard. Polycyclic aromatic hydrocarbons and organochlorines were identified and quantified using $\mathrm{GC} / \mathrm{MS}$, and $\mathrm{GC} / \mathrm{ECD}$, respectively.

The analytical procedure used on the sediment sample is a modification of the method suggested by Shim et al. (1999). Air-dried sediments were ground and weighed to about $5 \mathrm{~g}$ in $50 \mathrm{~m} l$ polypropylene centrifuge tubes. The samples were spiked with tripentyltin chlroride and digested with $10 \mathrm{~m} l$ of $6 \mathrm{~N} \mathrm{HCl}$, then subsequently extracted with $20 \mathrm{ml}$ methylene chloride with tropolone $(0.1 \%)$ by shaking for $3 \mathrm{~h}$. After $10 \mathrm{~min}$ centrifugation $(4,000 \mathrm{rpm}), 2 \mathrm{~m} l$ of organic extracts were transferred to $15 \mathrm{~m} l$ glass test tubes and concentrated to about $25 \mu l$ under a gentle stream of nitrogen. Then the samples were resuspended in $2 \mathrm{~m} / n$ hexane and derivatized with $250 \mu l$ of $2 \mathrm{M}$ propylmagnesium 


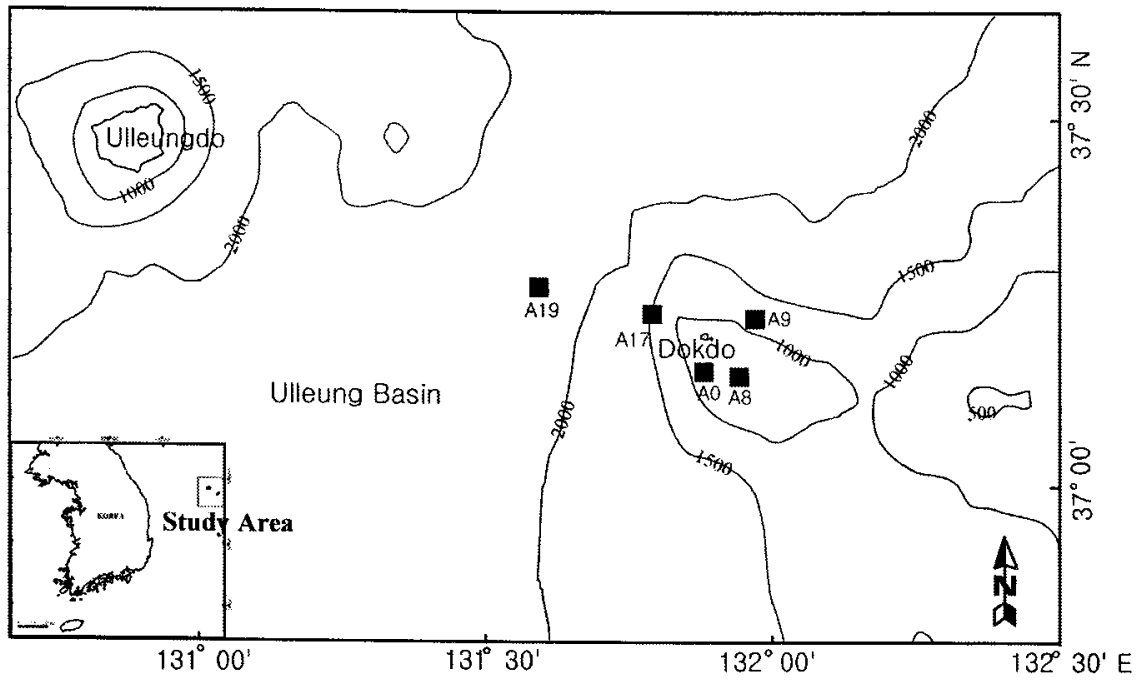

Fig. 1. Location map of surface sediment sampling sites near Dokdo. Core sediment samples were taken at A19.

chloride for $20 \mathrm{~min}$. The remaining Grignard Reagent was neutralized with $4 \mathrm{ml}$ of $0.4 \mathrm{~N}$ sulfuric acid. The organic phase was recovered by centrifugation and cleaned up on $2 \mathrm{~g}$ of activated florisil. The cleaned extracts were concentrated again and spiked with tetrabutyltin as an internal standard, and then analyzed by gas chromatograph (Hewlett Packard 5890 Series II) equipped with a capillary column (SPB-1, $30 \mathrm{~m} \times 0.25 \mathrm{~mm}$ i.d. $\times 0.25 \mu \mathrm{m}$ film thickness) and a flame photometric detector. The gas chromatograph operating condition was reported elsewhere (Shim et al., 1999).

Determination of the organophosphorus pesticides in sediment samples was performed using of the method of Yu et al. (2001). About $5 \mathrm{~g}$ of freeze-dried sediment sample was taken into a pre-cleaned extraction thimble in Sohxlet apparatus and extracted using hexane : acetone mixture (50:50). The extract was rotary vacuum evaporated to $2 \mathrm{~m} l$ and further concentrated to $0.5 \mathrm{~m} l$ by gentle nitrogen stream. The concentrated extracts were cleaned up by Florisil column. The eluent was concentrated to 1 $\mathrm{mL}$ then subjected to GC/NPD analysis.

Detection limit for each compounds are 0.001-0.005 ng/ $\mathrm{g} \mathrm{dw}$ (OCPs), 0.001-0.003 ng/g dw (PCBs), 0.05-0.25 ng/g $\mathrm{dw}$ (PAHs), $1 \mathrm{ng} \mathrm{Sn} / \mathrm{g} \mathrm{dw}$ (BTs), and $1 \mathrm{ng} / \mathrm{g} \mathrm{dw}$ (OPs). The acceptable range for surrogate recovery was $40-120 \%$, and if any sample deviate this criterion, that was reanalyzed. Procedural blank was analyzed with same batch of real sample. The criteria for procedural blank were none of target compounds exceeds 3 times the method detection limit. Certified reference materials (CRM) were also analyzed for quality assurance and target compounds in CRM satisfied the certified values.
Table 2. Trace organic contaminants in surface sediments from deep-sea near Dokdo.

\begin{tabular}{lccccc}
\hline & A0 & A8 & A9 & A17 & A19 \\
\hline${ }^{1}$ TOC (\%) & 1.47 & 3.21 & 3.61 & 3.98 & 2.09 \\
${ }^{2}$ PAHs & 29.3 & 14.8 & 118 & 37.1 & 314 \\
${ }^{3}$ PCB & nd & nd & 0.011 & nd & nd \\
${ }^{4} \mathrm{OCPs}$ & 1.89 & 0.165 & 2.97 & 2.70 & 3.04 \\
${ }^{5} \mathrm{OPs}$ & nd & nd & nd & nd & nd \\
${ }^{6} \mathrm{BTs}$ & nd & nd & nd & nd & nd \\
\hline
\end{tabular}

${ }^{\mathrm{I}}$ Total organic carbon.

${ }^{2}$ Sum of 24 target PAHs.

${ }^{3}$ Sum of 22 isomers.

${ }^{4}$ Sum of DDTs, HCHs, HCBs, CHLs, and Dieldrins.

${ }^{5} \mathrm{Sum}$ of six organophosphorous pesticides.

${ }^{6} \mathrm{Sum}$ of mono, di, and tributyltin.

"Not detected.

\section{Results and discussion}

\section{Surface sediments}

Polycyclic aromatic hydrocarbons

Total PAH concentrations in surface sediments ranged 14.8-314 ng/g dry weight (Table 2). Relatively low concentrations (14.8-37.1 ng/g) were found near Dokdo, while the highest concentration was found away from Dokdo, that site is more than $2,000 \mathrm{~m}$ deep. Concentration of total PAHs at A19 is several magnitude or order higher than other sites.

Most of studies have focused on the contamination of PAHs in the nearshore industrialized or urbanized regions (Table 3). As much as $10,000 \mathrm{ppm}$ of PAHs was found in the heavily contaminated harbor (Simpson et al., 1996). 
Table 3. Comparison of PAHs data in this study with other studies.

\begin{tabular}{lccccl}
\hline \multicolumn{1}{c}{ Location } & $\begin{array}{c}\text { Sample } \\
\text { No. }\end{array}$ & $\begin{array}{c}\text { Target } \\
\text { Analytes }\end{array}$ & Range & Instrument & Reference \\
\hline Nearshore & & & & & \\
Kyunggi Bay (Korea) & 66 & 24 & $9.1-1400$ & GC/MS & Kim et al. (1999) \\
Kitimat Harbor (Canada) & 20 & 16 & nd -10,000,000 & GC/FID & Simpso et al. (1996) \\
Casco Bay, Maine (USA) & 53 & 24 & $16-20,798$ & GC/MS & Kennicutt et al. (1994) \\
Western Mediterranean (Europe) & 23 & 26 & $1-20,500$ & GC/MS & Baumar et al. (1998) \\
Fjords (Norway) & 119 & 13 & $262-784,296$ & GC/MS, FID & Naes \& Oug (1998) \\
Sydney Harbor (Australia) & 124 & 17 & nd -380,000 & GC/MD & McCread et al. (2000) \\
Nationwide (Korea) & 92 & 24 & $1.19-28,640$ & GC/MD & MOMAF (2001) \\
Deep-sea & 5 & 24 & $14.8-314$ & GC/MD & This study \\
Dokdo & 1 & 3 & 8 & GC/MD & Laflamme \& Hites (1978) \\
Abyssal plain (North Atlantic) & 19 & 16 & $20-40$ & GC/MS, FID & Venkatesan \& Kaplan (1982) \\
Navarin Basin (Alaska) & 20 & 15 & $0.81-60.6$ & GC/MS & Ohkouch et al. (1999) \\
Deep-sea floor (Central Pacific) & & & & &
\end{tabular}

However there exists only few studies concerning deep-sea sediments. Total PAHs in the deep-sea sediments from central Pacific ranged from 0.81 to $60.6 \mathrm{ng} / \mathrm{g}$ dry weight (Ohkouchi et al., 1999). Other studies reported that total PAHs concentration in the abyssal plain (Laflamme and Hites, 1978) and outer continental shelf (Venkatesan and Kaplan, 1982) are far less than $100 \mathrm{ng} / \mathrm{g}$ dry weight. The highest concentration in A19 is comparable to those of moderately polluted regions Korean coastal area where total PAHs in surface sediments ranged from $1.19 \mathrm{ng} / \mathrm{g}$ (sand) to $28,640 \mathrm{ng} / \mathrm{g}$ with geometric mean of $290 \mathrm{ng} / \mathrm{g} \mathrm{dw}$ (MOMAF,
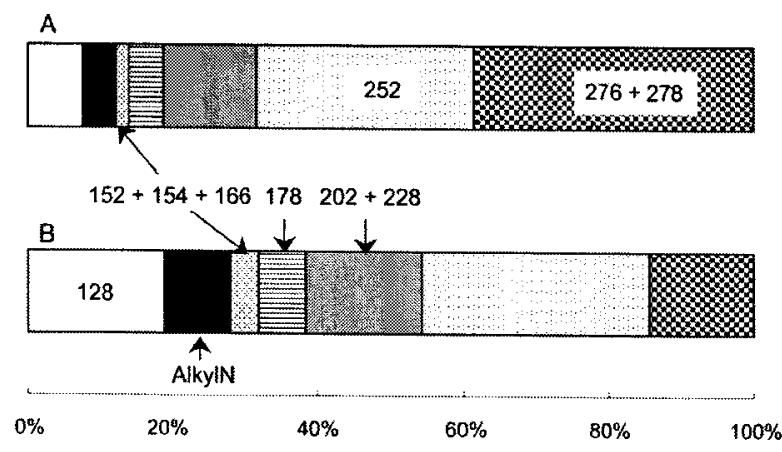

Fig. 2. Average composition profiles of PAHs in surface sediments near Dokdo. A. average of A19 and A9. B. Other sites. MW128: naphthalene; alkyl N: sum of C1 napththalene, 2,6 dimethylnaphthalene, 1,3,5 trimethylnaphthalene; $152+154+166$ : sum of biphenyl, acenaphthene, fuorene; 178: sum of phenanthrene, anthracene; 202+228: sum of fluoranthene, pyrene, benz[a]anthracene, chrysene, 252: sum of benzo[b]fluoranthene, benzo[k]fluoranthene, benzo [e]pyrene, benzo[a]pyrene, perylene; $276+278$ : Indeno (1,2,3-cd)pyrene, dibenz[a,h]anthracene, benzo [ghi]perylene.
2001).

Most of the target compounds were detected because large quantities of samples ( $15 \mathrm{~g}$ dry weight) were used for increasing detection limit. According to the composition of each site, two groups were defined. Group A comprises A0, A8 and group B stands for A9, A17 and A19. High molecular weight (molecular weight $\geq 202$ ) PAHs were dominant, which account for $61 \%$ and $81 \%$ in group $\mathrm{A}$ and $\mathrm{B}$, respectively. In group A, molecular weight (MW) $276+278$ was predominant and followed by 252 . While MW 252 was most dominant and followed by $128,202+228$ in group B (Fig. 2). These apparent compositional differences are mainly due to the input sources and will be discussed later.

\section{Organochlorine compounds}

Among the detected organochlorine compounds, DDT compounds were the dominant organochlorines with the mean concentrations of $0.6 \pm 0.89 \mathrm{ng} / \mathrm{g}$ and followed by HCHs $(0.25 \pm 0.41 \mathrm{ng} / \mathrm{g})$ and $\mathrm{HCB}(0.05 \pm 0.06 \mathrm{ng} / \mathrm{g})$. While, the concentrations of PCB, aldrin, endosulfan II, mirex, and chlordane compounds were below the detection limit values. This contamination levels were apparently lower than those previously reported from the coastal zone of Korea with concentration range of $0.01-135 \mathrm{ng} / \mathrm{g}$ for $\Sigma D D T$, nd-4.38 ng/g for $\Sigma \mathrm{HCH}$, nd-81 $\mathrm{ng} / \mathrm{g}$ for $\mathrm{HCB}$, and 0.09 $199 \mathrm{ng} / \mathrm{g}$ for $\Sigma$ PCB (MOMAF, 2001).

The concentration level of $\Sigma$ DDT in surface sediments from the nearby Dokdo was comparable with that of Gulf of Alaska (0.17 ng/g), Bering Sea $(0.006 \mathrm{ng} / \mathrm{g})$, and Chukchi Sea $(0.009 \mathrm{ng} / \mathrm{g}$ ) (Iwata et al., 1994), but lower than those of the Baltic Sea (1.9-6.9 ng/g; Strandberg et al., 1998). Four sites (A0, A8, A9, and A19) out of five 
sites showed relatively high DDT composition compared to total DDTs (0.6-0.8). The dominance of DDT might indicate recent input of DDT.

Among the four $\mathrm{HCH}$ compounds $(\alpha-\beta, \gamma, \delta$ isomer), $\alpha-\mathrm{HCH}$ was mostly abundant in surface sediments determined, and followed by $\beta$-HCH. Gamma- and $\delta$ isomer were not detected at all sites. Hexachlorocyclohexane compounds are volatile organochlorines and hence are globally transported through the atmosphere. Numerous studies measured these compounds in various environmental matrix from open ocean, pristine Artic and Antarctic where no local source exist (Iwata et al., 1993; Muir et al., 1995; Allen-Gill et al., 1997; Hargrave et al., 2000; Montone et al., 2001). Among the $\mathrm{HCH}$ isomers, it is known that $\alpha-\mathrm{HCH}$ has a strong tendency for global transportation. Therefore, $\alpha-\mathrm{HCH}$ in sediment samples could be expected to be originated from the atmospheric deposition.

\section{Other trace organic contaminants}

Organotin compounds, especially butyltins, are used as biocide in antifouling paints to prevent ship hulls from fouling. Three target butyltin compounds (mono-, di- and tributyltin) were below detection limits for seawater $(<0.1-0.3 \mathrm{ng} \mathrm{Sn} / \mathrm{L})$ and sediments (<1-3 ng Sn/g dry weight). In previous study, tributyltin (TBT) compound was detected in mussel sample (48 ng/g) from Dokdo (Shim, 2000). This is the quite low level of TBT in comparison with the mean TBT concentration $(566 \mathrm{ng} / \mathrm{g}$ ) in bivalves from the coastal environment of Korea (Shim, 2000), which indicates that there are boating activities, even limited, around the Island. When the rapid degradation of TBT in water column is taken into account (Seligman et al., 1988), water depth of about $2000 \mathrm{~m}$ at the stations could be too deep to accumulate TBT in sediment up to above the detection limit.

In this study, six kinds of organophosphorus pesticides were used as target compounds (Table 1). Among them, chlorpyrifos was only detected in sediment samples with low level and low frequency, its concentration ranged from detection limit to $0.05 \mathrm{ng} / \mathrm{g}$ dry weight. It has been well known that organophosphorus pesticides are rapidly decomposed in environment and their half life range from several days to about twenty days in water system (Medina et al. 1999). Although large quantities were widely used in agricultural areas and high levels of concentration were determined in the Korea (Yu et al. 2001) and Japan (Tsuda et al. 1996), their low concentration in this studied area suggest that most of them are mixed and decomposed during the transportation.

\section{Core sediment}

\section{Polycyclic aromatic hydrocarbons}

Core sediment samples were taken at A19 (Fig. 1), where trace organic contaminants and trace metal concentrations happened to be the highest (MOMAF, 2000). Total PAHs concentrations ranged $38.4-454 \mathrm{ng} / \mathrm{g}$ dry weight and showed decreasing trends depending on the depth. Subsurface (2-4 $\mathrm{cm}$ ) showed the highest concentration and mid depth (16$19 \mathrm{~cm}$ ) the lowest (Fig. 3). Core sediment can be divided into three groups according to principal component analysis (Fig. 4A). Group 1 comprises surface and sub-surface $(0-7 \mathrm{~cm})$, group 2 mid-depth $(10-22 \mathrm{~cm})$ and group 3 lowest depth (22$33 \mathrm{~cm}$ ), respectively. High molecular weight PAHs account for most of variations of the total PAHs $\left(\mathrm{r}^{2}=0.98, p<0.01\right)$ (Fig. 3, Fig. 4B).

Input source changes which could be inferred from PAHs composition, were distinct depending on each group. Molecular weight $276+278$, i.e., indeno(1,2,3-cd), dibenzo[a,h]anthracene, benzo[ghi]perylene were dominant in group 1 and followed by 252 and $202+228$. These high molecular weight PAHs which are primarily produced by incomplete combustion of carbonaceous materials, have high $\log \mathrm{K}_{\mathrm{ow}}$ values (6.04-6.86) and hence have high affinity to adsorb to particulate matter. However, the

\section{Concentration(ng/g dry weight)}

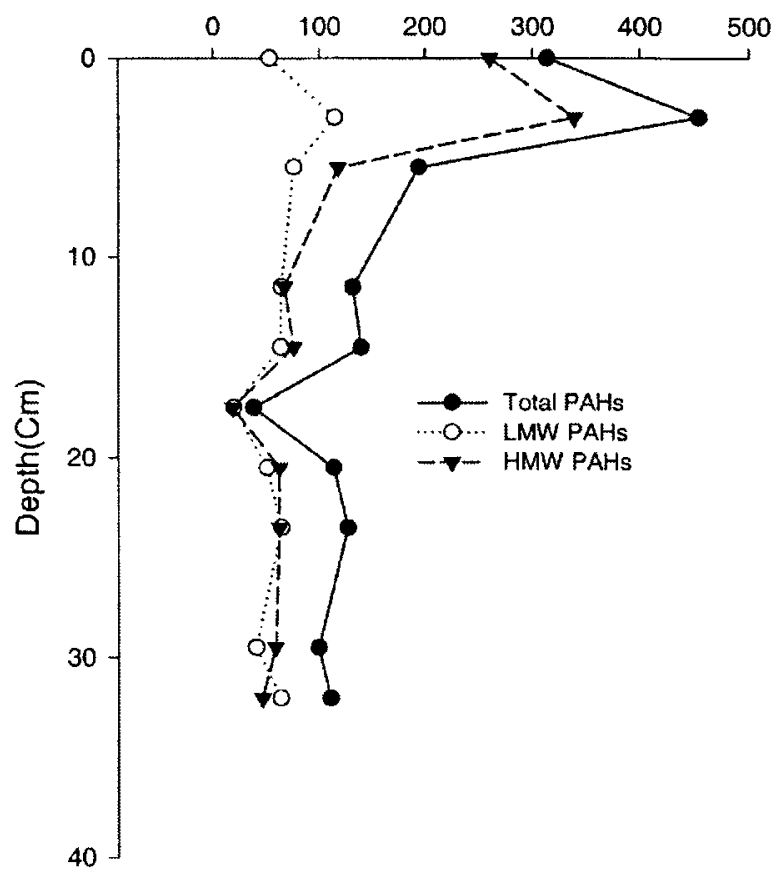

Fig. 3. Vertical distribution of total PAHs, low molecular weight and high molecular weight PAIs in core sediments from A19. 


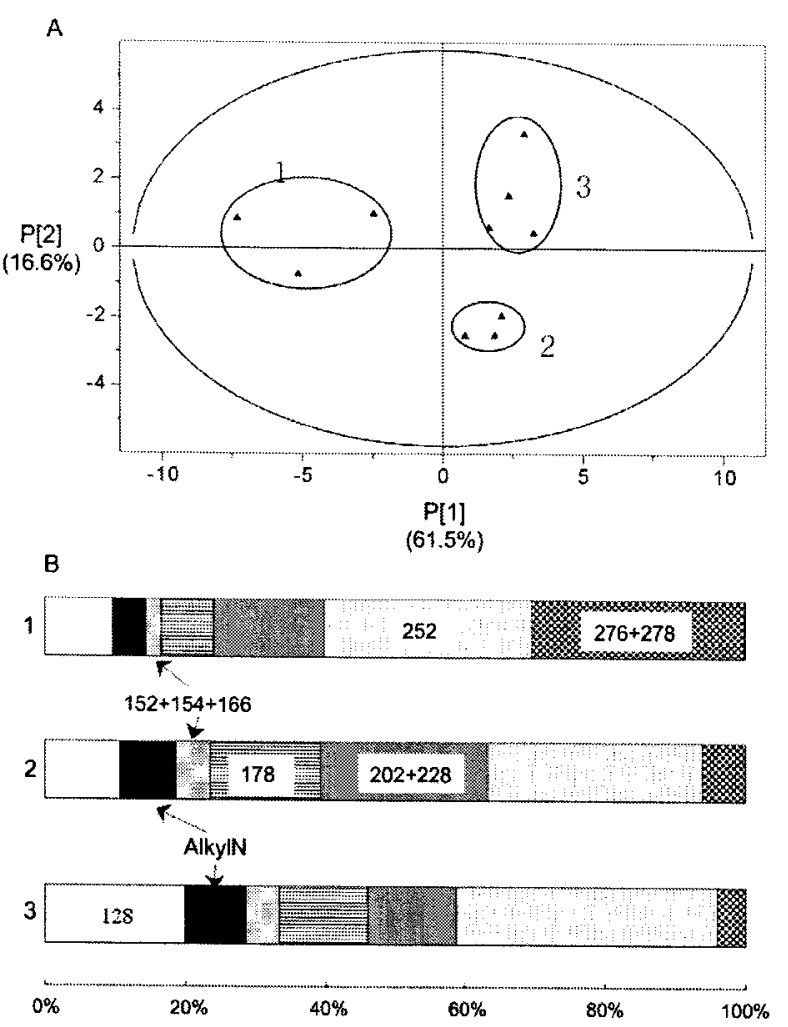

Fig. 4. Principal component analysis (A) and average composition profiles of sediment cores sampled at A19. 1. 0-7 cm, 2. 10-22 cm, 3. $22-33 \mathrm{~cm}$. Refer to caption of Fig. 2 for acronyms.

portion of MW 252 increases depending on depth and reached $34 \%$ in group 3. Naturally occurring PAHs, perylene which is known to be made by diagenesis in the presence of precursor compounds, account for these phenomena. The portion of perylene increased from $2.9 \%$ in surface sediments to $32.6 \%$ in deep sediment. According to Wakeham et al.(1980), perylene account for $70-90 \%$ of total PAHs in more than $1 \mathrm{~m}$ depth. In this study apparent increase of perylene less than $30 \mathrm{~cm}$ depth support the mechanism of perylene formation.

\section{Organochlorine compounds}

Similar with surface sediments, PCB compounds were not detected at all depth of core sediments. The highest concentrations of $\Sigma D D T$ and $\Sigma H C H$ were found at surface zone $(0-2 \mathrm{~cm})$ of core sediments. At the depth of $0-2 \mathrm{~cm}$ of core sediment, DDT composition (53\%) was relatively higher than those of its metabolites, DDD and DDE, similar to surface sediment $(60 \%)$, while DDE only determined at the lower depth. At surface layer, high proportion of DDT compound indicate the recent input of DDT compound.
While DDTs were only found within the depth of 0-7 $\mathrm{cm}, \mathrm{HCHs}$ were detected at all layers of sediment core. The concentrations of $\mathrm{HCH}$ compounds ranged from 0.06 to $0.48 \mathrm{ng} / \mathrm{g}$. At all depth, $\alpha-\mathrm{HCH}$ was the major isomer and followed by $\beta$-isomer, while $\gamma$ and $\delta$-isomer was not determined. In surface layer, the ratio of $\alpha$ - to $\beta$-isomer was 6.0 , which corresponds to that of original $\mathrm{HCH}$ mixture ( $\alpha$-: $\beta$-isomer $=55-80 \%, 5-14 \%$ ) (Walker et al., 1999). However, the ratio decreased according to the depth and this decreasing trend of $\alpha-/ \beta-\mathrm{HCH}$ would be due to high persistency of $\beta$-HCH among HCH compounds (Willet et al., 1998). Other target contaminants were not detected and this might due to the their lack of input sources and rapid degradation.

\section{Input sources}

Limited input sources lead study area relatively free of organic pollutants. However elevated concentrations of PAHs (314 ppb in A19) in deep-sea basin away from Dokdo brought about the question related to its sources. This abnormally elevated concentration is not confined to PAHs compounds. Some trace metals like manganese, mercury, and arsenic concentration also showed factors or order of magnitude higher than other sites (MOMAF, 2000). Atmospherically transported elements like lead didn't showed such elevation. Likewise, PAHs in remote areas are usually explained by atmospherically transported and deposited (Hites and Laflamme, 1980). But their geographical distribution should be uniform or at least have compositional consistency. As previously mentioned, geographical distribution and composition didn't support that they have been originated similar sources. Especially in core sediments there were distinct differences according to depth and these might be due to the source changes in the past.

Deep current which flows counterclockwise around the study area was simulated by Chang et al. (2000). This current pass through the dumping site "Byung". Into this dumping site, wastes disposal was initiated from 1988. Recently (1995-2000), 13.3 million tons of sludges from industrial wastewater have been dumped into this area (MOST, 2001). Takada et al. (1994) reported transport of organic pollutants derived from dumped sludge through the water column and accumulation on the deep-sea floor. They also observed resuspended surface sediments, which have high concentration of organic pollutant can be further dispersed by deep water transport processes. Speed of deep current in Ulleung basin reaches $5 \mathrm{~cm} / \mathrm{s}$ and this could be influential vector of organic pollutants derived from dumped sludge or resuspended sediments in dumping site.

There is only limited data related on status and geochemical 
processes of trace organic contaminants in the deep-sea. Considering that the deep-sea basin plays important role for final reservoir of these contaminants, further studies should be done. Deep-sea basin near Dokdo in this study happened to be possessing elevated levels of trace organic contaminants, especially PAHs. Relationship between input sources like dumping activity and large-scale oceanographic processes such as deep current, air-sea interaction should be further backed up by sediment trap, water-born contaminants, expansion of study area and atmospheric deposition.

\section{References}

Allen-Gil, S.M., C.P. Gubala, R. Wilson, D.H. Landers, T.L. Wade, and J.L. Sericano et al. 1997. Organochlorine pesticides and polychlorinated biphenyls (PCBs) in sediments and biota from four US Arctic Lakes. Arch. Environ. Contam. Toxicol., 33, 378-387.

Alzieu, C.L. 1986. TBT detrimental effects on oyster culture in France-evolution since antifouling paint regulation. Oceans 86. Proceedings of the Third International Organotin Symposium, Vol. 4. Institute of Electrical and Electronics Engineers, New York, pp.1130-1134.

Baumard, P., H. Budzinski, and P. Garrigue. 1998. PAHs in sediments and mussels of the Western Mediterranean Sea. Environ. Toxicol. Chem., 17, 765-776.

Chang, K.I., N.G. Hogg, M.S. Suk, S.K. Byun, K. Kim, and Y.G. Kim. 2002. Mean flow and variability in Southwestern East Sea. Deep-Sea Res. (In press).

Froescheis, O., R. Looser, G.M. Cailliet, W.M. Jarman, and K. Ballschimiter. 2000. The deep-sea as a final global sink of semivolatile persistent organic pollutants? Part I: PCBs in surface and deep-sea dwelling fish of the North and South Atlantic and the Monterey Bay Canyon (California). Chemosphere, 40, 651-660.

Hargrave, B.T., G.A. Phillips, W.P. Vass, P. Bruecker, H.E. Welch, and T.D. Siferd. 2000. Seasonality in bioaccumulation of organochlorines in lower tropic level Arctic marine biota. Environ. Sci. Technol., 34, 980-987.

Harris, C.R. and J.R.W. Miles. 1975. Pesticide residues in the Great Lakes region of Canada. Residue Review, 57, $27-79$.

Hites, R.A. and R.E. Laflamme. 1977. Sedimentary polycyclic aromatic hydrocarbons: the historical record. Science, 198, 829-831.

lwata, H., S. Tanabe, N. Sakal, and R. Tatsukawa. 1993. Distribution of persistent organochlorines in the Oceanic air and surface seawater and the role of ocean on their global transport and fate. Environ. Sci. Technol., 27, 10801098.
Iwata, H., S. Tanabe, N. Sakai, A. Nishimura, and R. Tatsukawa. 1994. Geographical distribution of persistent organochlorines in air, water and sediments from Asia and Oceania, and their implications for global redistribution from lower latitudes. Environ. Pollut., 85, 15-33.

Kennicutt II, M.C., T.L. Wade, B.J. Presley, A.G. Requejo, J.M. Brooks, and G.J. Denoux. 1994. Sediments contaminants in Casco Bay, Maine: inventories, sources, and potential for biological impact. Environ. Sci. Technol., 28, $1-15$.

Khim, J.S., K. Kannan, D.L. Villeneuve, C.H. Koh, and J.P. Giesy. 1999. Characterization and distribution of trace organic contaminants in sediment from Masan Bay, Korea. 1. Instrumental analysis. Environ. Sci. Tech., 33, 4199-4205.

Kim, G.B., K.A. Maruya, R.F. Lee, J.H. Lee, C.H. Koh, and S. Tanabe. 1997. Distribution and sources of PAHs in Kyeonggi Bay, Korea. Mar. Pollut. Bull., 38, 7-15.

Krahn, M.M. and L.K. Moore. 1988. High performance liquid chromatographic method for isolating organic contaminants from tissue and sediment extracts. J. Chromatogr., 437, 161-175.

Krämer, W., H. Buchert, U. Reuter, M. Biscoito, D.G. Maul, G. LeGrand, and K. Ballschmiter. 1984. Global baseline studies IX: C6-C14 organochlorine compounds in surface waters and deep-sea fish from the Eastern North Atlantic. Chemosphere, 12, 1255-1267.

Laflamme, R.E. and R.A. Hites. 1978. The global distribution of PAHs in recent sediments. Geochim. Cosmochim. Acta., 42, 289-303.

Lauenstein, G.G. and A.Y. Cantillo. 1998. Sampling and analytical methods of the National Status and Trends Program Mussel Watch Project. 1993-1996. MA, NOAA.

McCready, S., D.J. Slee, G.F. Birch, and S.E. Taylor. 2000. The distribution of polycyclic aromatic hydrocarbons in surficial sediments of Sydney Harbour, Australia. Mar. Pollut. Bull., 40(11), 999-1006.

McElroy, A.E., J.W. Farrington, and J.M. Teal. 1989. Bioavailibility of PAHs in aquatic environment. In Metabolism of PAHs in aquatic environment: pp.2-33. CRC Press Inc. Boca Raton, Florida.

Medina, D., A. Prieto, G. Ettiene, I. Buscema, and A. Avreu de V. 1999. Persistence of organophosphorus pesticide residues in Limón River waters. Bull. Environ. Contam. Toxicol., 63, 39-44.

MOMAF. 2000. Baseline studies of Dok Island ecosystem. BSPM 99045-00-1282-6. Ministry of Maritime Affairs and Fisheries, Seoul, Korea (in Korean).

MOMAF. 2001. The status of POPs contamination along the 
coast of Korea. BSPM00070-00-1336-3, 3-15, Ministry of Maritime Affairs and Fisheries, Seoul, Korea (in Korean).

MOST. 2001. Marine environmental conservation technology: Development of monitoring technology for the wastes disposal sea areas. BSPN 421-00-1366-4. 76-80. Ministry of Science and Technology, Seoul Korea (in Korean).

Montone, R.C., S. Taniguchi, and R.R. Weber. 2001. Polychlorinated biphenyls in marine sediments of Admiralty Bay, King George Island, Antarctica. Mar: Pollut. Bull., 42(7), 611-614.

Muir, D.C.G., N.P. Grift, W.L. Lockhart, P. Wilkinson, B.N. Billeck, and G.J. Brunskil. 1995. Spatial trends and historical profiles of organochlorine pesticides in Arctic lake sediments. Sci. Total Environ., 160/161 447-457.

Naes, K and E. Oug. 1998. The distribution and environmental relationships of PAHs in sediments from Norwegian smelter-affected fjords. Chemosphere, 36, 561-576.

Ohkouch, N., K. Kawamura, and H. Kawahata. 1999. Distribution of three- to seven-ring polycyclic aromatic hydrocarbons on the deep sea floor in the central Pacific. Environ. Sci. Technol., 33, 3086-3090.

Seligman, P.F., A.O. Valkirs, P.M. Stang, and R.F. Lee. 1988 Evidence for rapid degradation of tributyltin in a marina. Mar. Pollut. Bull., 19, 531-534.

Shim, W.J. 2000. A study on environmental chemistry and toxicology of organotins in the marine environment of Korea. Ph.D thesis, Seoul National University, Seoul, Korea. 263 pp.

Shim, W.J., J.R. Oh, S.H. Kahng, J.H. Shim, and S.H. Lee. 1999. Horizontal distribution of butyltins in surface sediments from an enclosed bay system, Korea. Environ. Pollut., 106(3), 351-357.

Simpson, C.D., A.A. Mosi, W.R. Cullen, R.A. Bright, and KJ. Reimer. 1996. Composition and distribution of polycyclic aromatic hydrocarbon contamination in surficial marine sediments from Kitimat Harbor, Canada. Sci. Tot. Environ., 181, 265-278.
Sloan, C.A. and N.G. Adams. 1993. Northwest fisheries science center organic analytical procedures. NOAA Technical Memorandum NOS ORCA 71, 53-97.

Stein, J.E., W.L. Reichert, M. Nishimoto, and U. Varanasi. 1990. Overview of studies on liver carcinogenesis in English sole from Puget Sound; evidence for a xenobiotic chemical etiology II: biochemical studies. Sci. Tot. Environ., 94, 51-69.

Takada, H., J.W. Farrington, M.H. Bothner, C.G. Johnson, and B.W. Tripp. 1994. Transport of sludge-derived organic pollutants to deep-sea sediments at deep water Dump Site 106. Environ. Sci. Tech., 28, 1062-1072.

Tsuda, T., T. Inoue, M. Kojima, and S. Aoki. 1996. Pesticides in water and fish from rivers flowing into Lake Biwa. Bull. Environ. Contam. Toxicol., 57(3), 442-449.

Venkatesan, M.I. and I.R. Kaplan. 1982. Distribution and transport of hydrocarbons in surface sediments of the Alaskan outer continental shelf. Geochim. Cosmochim. Acta., $46,2135-2149$.

Wakeham, S.G. and C. Schaffner. 1980. Polycyclic aromatic hydrocarbons in recent lake sediments-II. Compounds derived from biogenic precursors during early diagenesis. Geochim. Cosmochim. Acta., 44, 415-429.

Walker, K., D.A. Vallero, and R.G. Lewis. 1999. Factors influencing the distribution of lindane and other hexachlorocychlohexanes in the environment. Environ. Sci. Technol., 33(24), 4373-4378.

Willett, K.L., E.M. Ulrich, and R.A. Hites. 1998. Differential toxicity and environmental fates of hexachlorocyclohexane isomers. Envion. Sci. Technol,, 32(15), 2197-2207.

Yu, J., D.H. Lee, K.T. Kim, D.B. Yang, and J.S. Yang. 2001. Distribution of organophosphorus pesticides in some estuarine environments in Korea. J. Fish. Sci. Tech., 4(4), 201207.

Received Nov. 20, 2002

Accepted Dec. 24, 2002 